\title{
Iron Nanoparticles in Reactive Environmental Barriers
}

Eric E. Nuxoll, Tsutomu Shimotori, William A. Arnold and Edward L. Cussler

Dept. of Chemical Engineering \& Materials Science

Dept. of Civil Engineering

University of Minnesota

Minneapolis, MN 55455

Prepared for Presentation at the AIChE Annual Meeting, November 20, 2003

Session: Membranes in Environmental Applications II

CEric E. Nuxoll, Tsutomu Shimotori, William A. Arnold \& Edward L. Cussler University of Minnesota, Minneapolis, MN

September 23, 2003.

Unpublished.

Portions of material contained herein are taken from the doctoral dissertation

"Transient Transport in Reactive Barrier Membranes",

CEric E. Nuxoll, 2003, with permission.

AIChE Shall Not Be Responsible For Statements or Opinions

Contained in Papers or Printed in its Publications.

\begin{abstract}
:
Zero-valent iron is cheap, environmentally innocuous, and effective at reducing chlorinated organics. It has, as a result, become a popular candidate for remediating aquifers contaminated with trichloroethylene and other halogenated pollutants. In this paper, we discuss one such system, where iron nanoparticles are synthesized and incorporated into polyvinyl alcohol membranes, forming water-permeable barriers to these pollutants. These barriers are tested against a variety of contaminants, including carbon tetrachloride, copper, and chromate.

The success (and, in some cases, failure) of these membranes offer several insights regarding the design and application of reactive barrier films for environmental remediation. These iron membranes are especially effective at blocking copper, potentially opening a new avenue of metal / radionuclide remediation applications. They might also, by prudent choice of polymer, be made into preventative barriers which would line potential pollution sites such as landfills or tank farms.

The economic advantages of using larger iron particles are clear, but the drawbacks due to reduced effectiveness are not so straightforward and may, in fact, change with the application. We build upon our existing theory to predict how the particle size (and hence, the effective reaction rate of the system) should affect contaminant diffusion through the membranes.
\end{abstract}




\section{Introduction}

Environmental problems are a major area of application for barrier membranes. Many industrially important chemicals are known toxins which can wreak havoc when released into the ecosystem. Some do not naturally degrade, persisting for years while being spread through the water table. Keeping these chemicals out of our aquifers-and removing the ones already there-is a major environmental priority, and an obvious application for barrier membranes.

The addition of scavengers to the membrane is an especially attractive idea in these circumstances, since the membrane would then not only block the pollutant from entering the protected region downstream, but also consume the pollutant upstream, leaving that region cleaner as well. The reaction products, of course, must be less toxic than the pollutants, and the scavenger itself must be non-toxic to be allowed into the ground. Being inexpensive doesn't hurt, either.

Elemental iron appears to best fit these criteria. The second-most common element in the Earth's crust ${ }^{1}$, it is cheap, innocuous, and effective at removing a host of pollutants. Senzaki et $\mathrm{al}^{2}$ showed that iron was effective at reducing halogenated organics just over a decade ago, tripping an avalanche of research into its uses. Chlorinated organics contribute to a variety of health problems in humans, particularly cancer, ${ }^{3}$ and make up ten of the 25 most frequently detected groundwater contaminants at hazardous waste sites. ${ }^{4}$ The dechlorination of these compounds by iron has been widely studied ${ }^{5-11}$ and continues to expand as more pollutants are tested against it. Iron has also been shown to reduce nitrates, ${ }^{12}$ bromates, ${ }^{12}$ chlorates, ${ }^{12}$ nitroaromatic compounds, ${ }^{13-14}$ and brominated ${ }^{15}$ or carbarylated ${ }^{16}$ pesticides. It has been shown effective at removing arsenic, ${ }^{17}$ lead, ${ }^{18}$ uranium, ${ }^{19}$ and hexavalent chromium ${ }^{18,20}$ from water, as well as promoting the biodegradation of azo dyes. ${ }^{21}$ Tests for reducing cockroaches and the general malaise may be upcoming.

Iron geo-barriers have already been installed in a variety of locations for the remediation of aquifers contaminated with chlorinated organics. ${ }^{22-25}$ The reactive layer typically consists of a few meters of free iron contained on each side by gravel. The water flows through the bed of iron, which reacts with the pollutants. More recently, Zhang $e a^{26-27}$ published a recipe for synthesizing iron nanoparticles, which presumably have a much higher reaction rate per volume than larger iron particles, since the reaction occurs at the iron surface. ${ }^{10}$ A bed of such small particles would be difficult to maintain, but by immobilizing them in another medium, we propose that they could be harnessed into an effective barrier. For our matrix we used PVA. The iron nanoparticles are synthesized with a recipe adapted from Zhang et al, ${ }^{26-27}$ and our target solutes are carbon tetrachloride, a model chlorinated organic, and copper, which also appears on the 'top 25' list of ground-water contaminants. ${ }^{4}$

\section{Membrane Synthesis}

Membrane syntheses were performed in a glove box (TM-Vacuum Products, model \#GDO-2400-1) with a drying column which scavenged both oxygen and water. During synthesis, the box was typically kept to an oxygen concentration below $1000 \mathrm{ppm}$. Water used in the synthesis was distilled, then boiled for at least 30 minutes to deoxygenate before immediate transfer into the box. It was left to cool before use.

$2.0 \mathrm{~g}$ of Dupont Elvanol 71-30 PVA was added to a $50 \mathrm{~mL}$ beaker containing a stir bar and $20 \mathrm{~mL}$ of water. The beaker was covered with Parafilm and set to stirring and heat (setting " 3 ") on a Corning $698 \mathrm{~W}$ heat/stir plate for a few hours until dissolved. $100 \mathrm{~mL} \mathrm{H}_{2} \mathrm{O}$ was added to $1.35 \mathrm{~g} \mathrm{FeCl}_{3} 6 \mathrm{H}_{2} \mathrm{O}$ (Aldrich) in a $250 \mathrm{~mL}$ Erlenmeyer flask and swirled by hand. The $\mathrm{FeCl}_{3}$ dissolved in a couple minutes, turning the solution bright yellow. $1.30 \mathrm{~g} \mathrm{NaBH}_{4}$ (Aldrich) was added to a $400 \mathrm{~mL}$ beaker, followed by $100 \mathrm{~mL} \mathrm{H} \mathrm{H}_{2} \mathrm{O}$ decanted on the beaker wall to flush down $\mathrm{NaBH}_{4}$ clinging to the surface. This mixture was also gently swirled by hand to quicken dissolution, generating a few minute bubbles.

To mix the two solutions without magnetic stirring (for fear of accumulating iron particles on the stir bar) the iron solution was jetted into the borohydride solution using a $12 \mathrm{~mL}$ syringe. The aim of the jet roamed around the interior of the beaker without hitting the walls. The solutions reacted violently on contact according to Equation $2.1^{26}$,

$$
2 \mathrm{FeCl}_{3}+6 \mathrm{NaBH}_{4}+18 \mathrm{H}_{2} \mathrm{O} \rightarrow 2 \mathrm{Fe}^{0}+6 \mathrm{NaCl}+6 \mathrm{~B}(\mathrm{OH})_{3}+21 \mathrm{H}_{2}
$$

generating hydrogen gas which contributed to the mixing. Total transfer of the iron solution took about one minute. The mixture was left to settle for a few hours while the iron particles grew, agglomerated, and settled. Water was carefully poured off the top of the mixture, replaced by fresh water, and swirled gently by hand for several seconds. This washing was repeated twice more, allowing several hours in between for the particles to again agglomerate and settle. After the third washing, the iron mixture and the PVA solution were placed in the box airlock and subjected to vacuum $(\sim 25 \mathrm{in} . \mathrm{Hg})$ overnight to degas the PVA and further protect the iron nanoparticles from oxygen.

Once removed from the airlock, the water was poured off from the iron mixture and the remaining iron-nanoparticle slurry was poured into the PVA solution. The mixture was carefully hand-mixed with a spatula for several minutes, then placed in an ice bath and sonicated for five minutes at $50 \mathrm{~W}$ and $20 \mathrm{kHz}$ using an ultrasonic homogenizer (Cole Parmer), and hand-mixed again for several more minutes. Some membranes were simply cast in plastic Petri dishes, while others were cast on Teflon or glass blocks and spread with a doctor blade. They dried for a few days in the glove box and were removed once dry. 
We then peeled the membranes from their substrate, cut SEM samples from them and hung them in a vacuum oven (Yamato ADP-31). We evacuated the oven to a vacuum of $70 \mathrm{cmHg}$, then flushed the oven with $\mathrm{N}_{2}$ three times, each time bring the oven back down to $70 \mathrm{cmHg}$ vacuum afterwards. Finally, we turned on the oven and set it to 150 degrees $\mathrm{C}$. After 135 minutes we turned off the oven and removed the membrane. It was then stored dry until tested.

SEM images of both the particles and the films were taken using a JEOL-6500 FEG-SEM. The particles were prepared for imaging by placing a drop of iron-nanoparticle slurry on a SEM sample stub and letting it dry in the glove box. The membrane samples were freeze-fractured using liquid $\mathrm{N}_{2}$. Membrane pieces were then mounted on a SEM sample stub covered with colloidal graphite. The membrane samples were coated with $50 \AA$ of carbon by technologists in the UMN Shephard Laboratories. Figures 1 and 2 show neat iron particles and the surface of an iron-laden membrane, respectively.

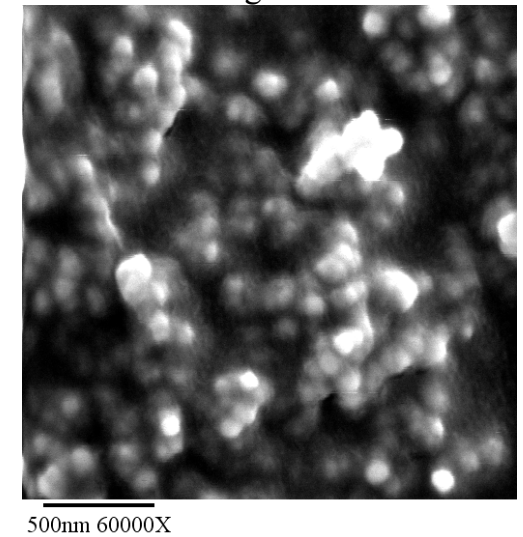

Figure 1: Iron Nanoparticles

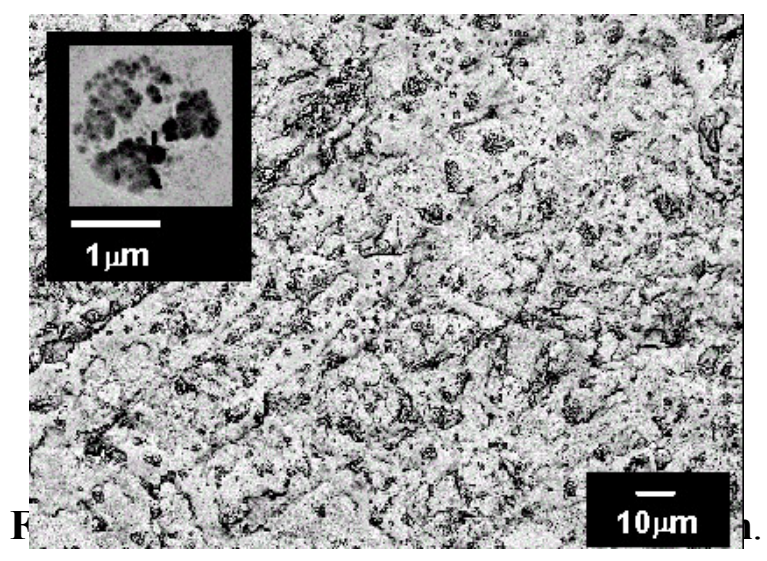

\section{Barrier Testing}

We measured transport of both carbon tetrachloride and copper chloride across the membranes using a diaphragm cell $^{28}$. Ports were installed in the upstream chamber (now of Pyrex, not Teflon) to flush continuously with fresh feed solution. This helped alleviate the problem of upstream solute depletion. A liter of freshly prepared stock solution was pumped into the upstream chamber with a peristaltic pump (Cole Parmer). Solute enters a reactive film more quickly when the upstream film face is still enriched with scavenger, so the initial flow rates of stock solution were higher than the rate later in the experiments. A typical flow rate schedule for $\mathrm{CCl}_{4}$ experiments is given in Table 1. Non-reactive experiments, where no solute is consumed, were performed in cells without flushing. The solvent for all experiments was deoxygenated water held at a $\mathrm{pH}$ of 7.2 with a Tris buffer.

Since the solutes are not easily monitored with probes, the probe ports were sealed with Teflon-coated septa and $10 \mu \mathrm{L}$ samples were periodically removed from the chambers via syringe. The analysis method depended on the analyte in question. Carbon tetrachloride was monitored by gas chromatography (ThermoQuest Trace2000) using a DB-1 column (J\&W Scientific) and an ECD detector. The samples were diluted in pentane to bring their concentrations within appropriate limits $(<200 \mu \mathrm{M})$ for the detector. Copper (II) was translated to visible signals by the bathocuproine method ${ }^{29}$, as described by the American Public Health Association. These visible signals were quantified with a UV/Vis spectrophotometer (Shimadzu UV-1601PC). Dissolved iron was also observed using the FerroZine method. ${ }^{30}$

\begin{tabular}{|c|c|}
\hline \multicolumn{2}{|c|}{$\begin{array}{l}\text { Table 1: Flushing Schedule } \\
\text { for Upstream Diaphragm Cell }\end{array}$} \\
\hline Time from Start & Flow $(\mathrm{mL} / \mathrm{min})$ \\
\hline $0-1$ hour & 1.73 \\
\hline $1-3$ hours & 0.84 \\
\hline $3-5$ hours & 0.42 \\
\hline $5-7$ hours & 0.22 \\
\hline $7-9$ hours & 0.11 \\
\hline 9 hours - end & 0.06 \\
\hline
\end{tabular}

\section{Results}

Figure 3 shows the breakthrough plot for $\mathrm{CCl}_{4}$ across a pure PVA membrane. From the steady-state asymptote, we find $\mathrm{D}=1.05 \cdot 10^{-6} \mathrm{~cm}^{2} / \mathrm{s}$ and $\mathrm{H}=0.422$. Figure 4 shows a similar plot for an iron-laden PVA membrane, with a lag time of 353 minutes and a permeability of $3.55 \cdot 10^{-7} \mathrm{~cm}^{2} / \mathrm{s}$. The lag time increased by a factor of 340 while the permeability changed by less than $20 \%$. Figure 5 shows $\mathrm{CCl}_{4}$ breakthrough across a second iron-laden PVA film with a comparable increase in lag time. A summary of all iron-laden PVA breakthrough experiments is given in Table 2. 

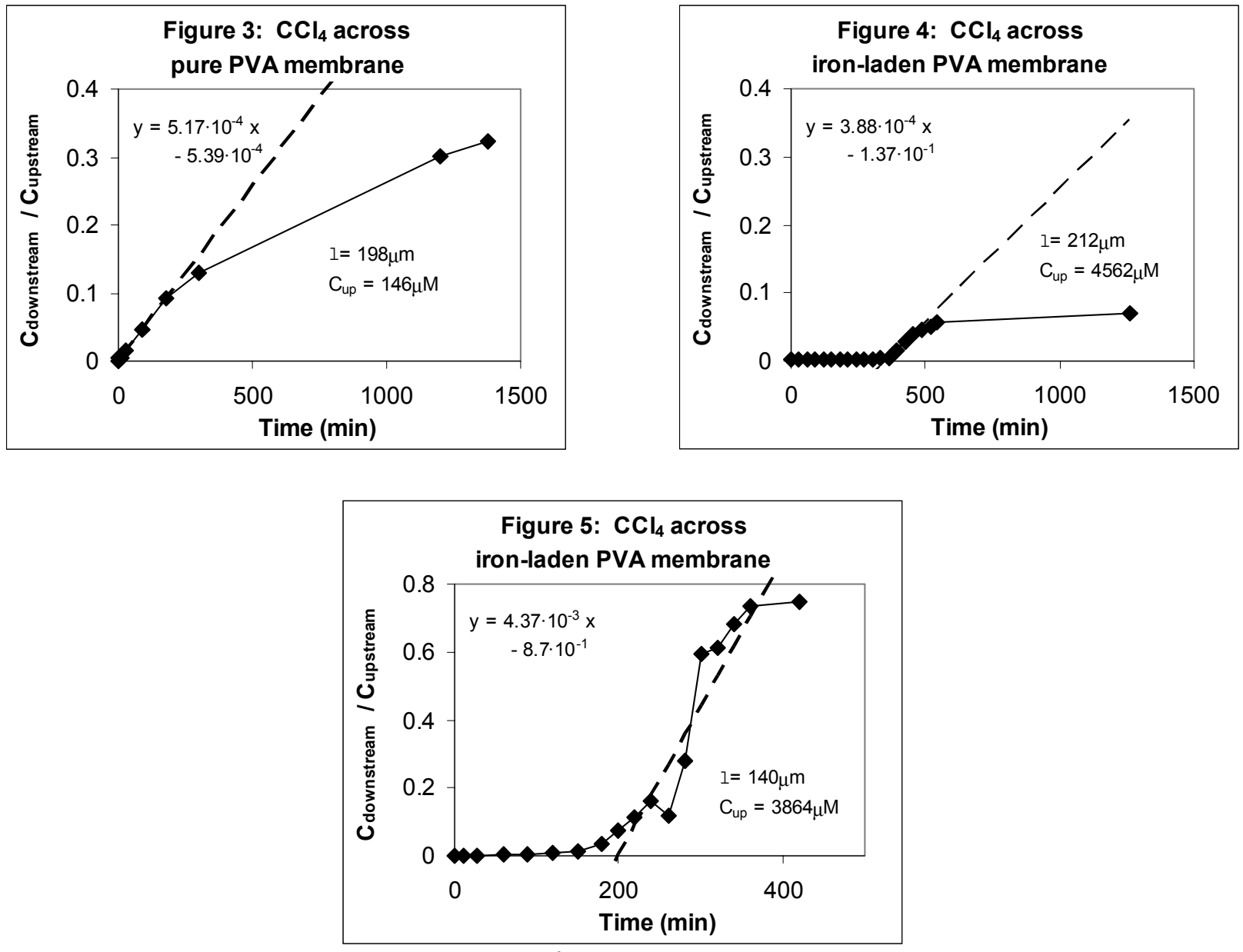

Figures $6-9$ show breakthrough plots for $\mathrm{Cu}^{2+}$ across four membranes. For Figure 6, a pure PVA membrane is used, from which we find $\mathrm{D}=2.82 \cdot 10^{-7} \mathrm{~cm}^{2} / \mathrm{s}$ and $\mathrm{H}=0.632$, giving a permeability of $4.46 \cdot 10^{-7} \mathrm{~cm}^{2} / \mathrm{s}$. The other three films have iron nanoparticles, and we see substantial increases in lag time for each of them. Figures 8 and 9 each have two plots since these films were tested twice. We see that on second application, when the iron has presumably been used up, there is no improvement in lag time. A summary of these experiments is also given in Table 2.
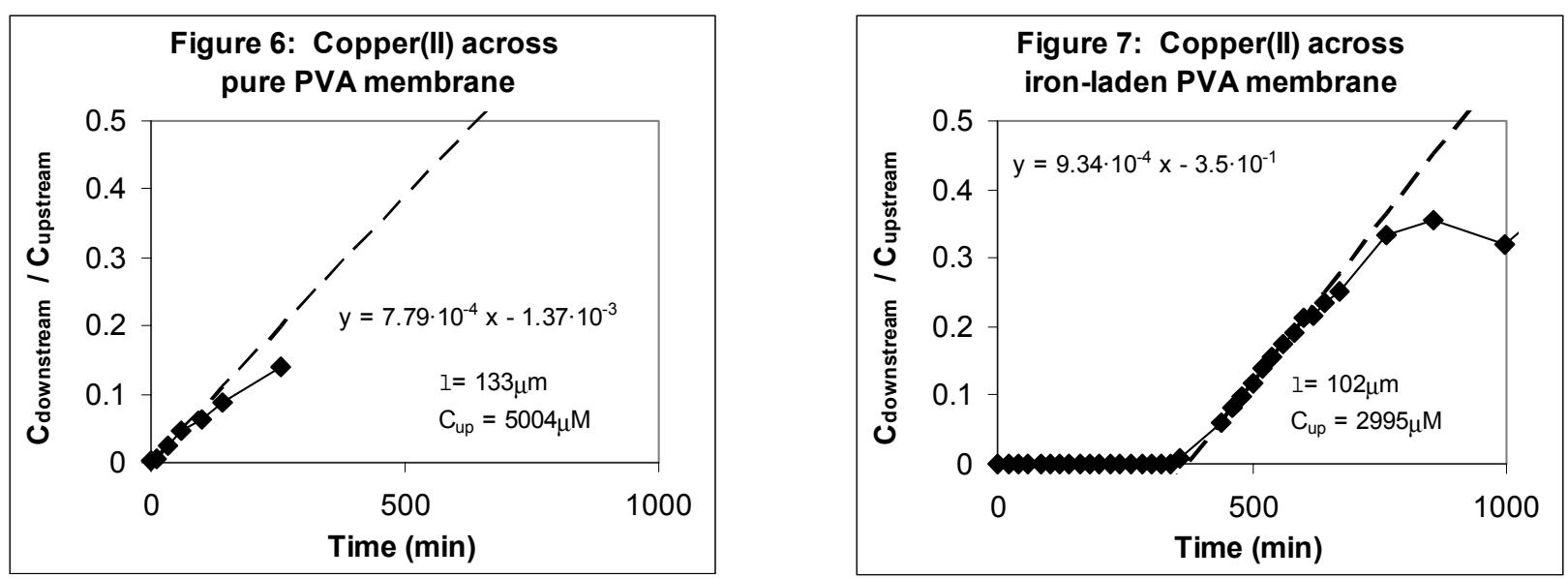

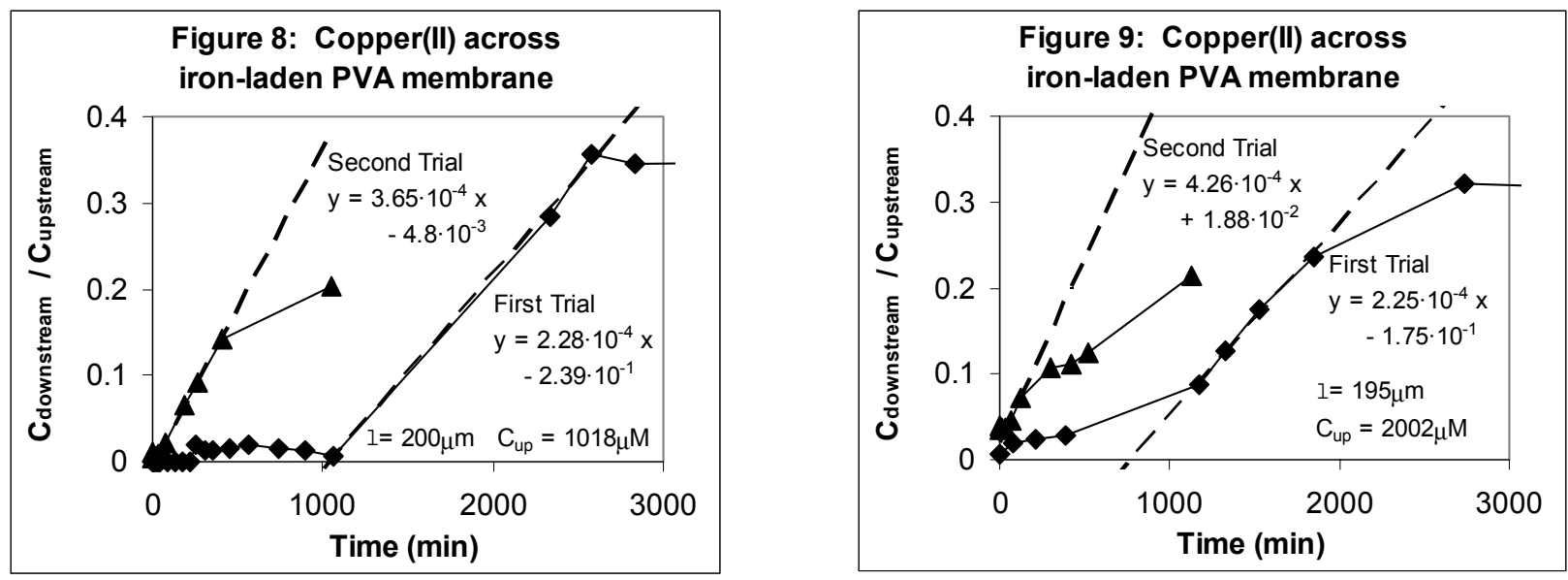

\begin{tabular}{|c|c|c|c|c|}
\hline \multicolumn{5}{|c|}{ Table 2: Fe/PVA Barrier Summary } \\
\hline Solute & Fe conc. [M] & Thickness $[\mu \mathrm{m}]$ & Lag time $[\mathrm{min}]$ & Permeability $\left[\mathrm{cm}^{2} / \mathrm{s}\right]$ \\
\hline $\mathrm{CCl}_{4}$ & 0 & 198 & 1.04 & $4.42 \cdot 10^{-7}$ \\
\hline $\mathrm{CCl}_{4}$ & 1.24 & 212 & 353 & $3.55 \cdot 10^{-7}$ \\
\hline $\mathrm{CCl}_{4}$ & 1.24 & 140 & 199 & $2.64 \cdot 10^{-6}$ \\
\hline $\mathrm{Cu}^{2+}$ & 0 & 133 & 1.74 & $4.46 \cdot 10^{-7}$ \\
\hline $\mathrm{Cu}^{2+}$ & 1.25 & 102 & 374 & $4.12 \cdot 10^{-7}$ \\
\hline $\mathrm{Cu}^{2+}$ & 0.44 & 200 & 1048 & $3.15 \cdot 10^{-7}$ \\
\hline $\mathrm{Cu}^{2+}$ & 0.44 & 195 & 778 & $1.9 \cdot 10^{-7}$ \\
\hline
\end{tabular}

\section{Discussion}

All of the data demonstrate a dramatic increase in lag time with the addition of iron. The barriers work. They do not, however, work as well as might be predicted. Applying the theory of Yang $e t$ al, ${ }^{28}$ we predict the lag times of the reactive films based on solute breakthrough in pure PVA films and the concentration of iron in the reactive ones. These predictions are over twice as large as the observed lag times for copper barriers and five times larger than observed for $\mathrm{CCl}_{4}$ barriers. Additional work by Shimotori ${ }^{31}$ however, suggests that nearly half of the iron is oxidized by water and dissolves out of the film before and during the experiment. This nearly closes the iron balance for the copper barriers. In the $\mathrm{CCl}_{4}$ barriers, the remaining iron may still be in the membranes, sealed off from reaction under a ferric shell, which explains the membranes' brownish-orange color. Research on this problem is ongoing.

With lag time increases of over 300 by adding just one percent by volume of iron, our data suggest that practical barriers, with lag times of decades, may be made with thicker films of more impervious material, such as high-density polyethylene, with a higher iron content. Immobilization in a less hydrophilic substrate may also sharply curb the iron losses due to water oxidation as well. The economic incentive would have to be substantial, however, as the iron nanoparticle synthesis is clearly neither cheap nor easy. Nonetheless, this appears to be a viable alternative for aquifer protection.

\section{References:}

1. The Merck Index. 12th ed, ed. S. Budavari. 1996, Whitehouse Station, NJ: Merck Research Laboratories.

2. Senzaki, T. and Y. Kumagai, Treatment of 1,1,2,2-Tetrachloroethane with iron powder. Kogyo Yosui, 1988. 357(1): p. $2-7$.

3. Bruckner, J.V., B.D. Davis, and J.N. Blancato, Metabolism, Toxicity, and Carcinogenicity of Trichloroethylene. Critical Reviews in Toxicology, 1989. 20(1): p. 31-50.

4. NRC, N.R.C., Alternatives for Groundwater Cleanup. 1994, Washington, D.C.: National Academies Press.

5. Gillham, R.W. and S.F. O'Hannesin, Enhanced Degradation of Halogenated Aliphatics by Zero-Valent Iron. Ground Water, 1994. 32(6): p. 958-967.

6. Matheson, L.J. and P.G. Tratnyek, Reductive Dehalogenation of Chlorinated Methanes by Iron Metal. Environmental Science \& Technology, 1994. 28(12): p. 2045-2053. 
7. Lipczynska-Kochany, E., Harms, S., Milburn, R., Sprah, G. and N. Nadarajah, Degradation of Carbon Tetrachloride in the presence of iron and sulphur containing compounds. Chemosphere, 1994. 29(7): p. 1477-1489.

8. Weber, E.J., Iron-Mediated Reductive Transformations: Investigation of Reaction Mechanism. Environmental Science \& Technology, 1996. 30(2): p. 716-719.

9. Johnson, T.L., Fish, W., Gorby, Y.A. and P.G. Tratnyek, Degradation of carbon tetrachloride by iron metal: Complexation effects on the oxide surface. Journal of Contaminant Hydrology, 1998. 29: p. 379-398.

10. Ruiz, N., S. Seal, and D. Reinhart, Surface chemical reactivity in selected zero-valent iron samples used in groundwater remediation. Journal of Hazardous Materials, 2000. B80: p. 107-117.

11. Choe, S., Lee, S.H., Chang, Y.Y., Hwang, K.Y. and J. Kim., Rapid reductive destruction of hazardous organic compounds by nanoscale Fe. Chemosphere, 2001. 42: p. 367-372.

12. Westerhoff, P., Reduction of Nitrate, Bromate, and Chlorate by Zero Valent Iron. Journal of Environmental Engineering, 2003. 129(1): p. 10-16.

13. Agrawal, A. and P.G. Tratnyek, Reduction of Nitro Aromatic Compounds by Zero-Valent Iron. Environmental Science \& Technology, 1996. 30(1): p. 153-160.

14. Mantha, R., Biswas, N., Taylor, K. and J.K. Bewtra, Removal of Nitroaromatics from Synthetic Wastewater Using Two-Step Zero-Valent Iron Reduction and Peroxidase-Catalyzed Oxidative Polymerization. Water Environment Research, 2002. 74(3): p. 280-287.

15. Loraine, G.A., Burris, D.R., Li, L. and J. Schoolfield, Mass Transfer Effects on Kinetics of Dibromoethane Reduction by Zero-Valent Iron in Packed Bed Reactors. Journal of Environmental Engineering, 2002. 128(1): p. 8593.

16. Ghauch, A., Gallet, C., Charef, A., Rima, J. and M. Martin-Bouyer, Reductive degradation of carbaryl in water by Zero-valent iron. Chemosphere, 2001. 42: p. 419-424.

17. Ramaswami, A., S. Tawachsupa, and M. Isleyen, Batch-mixed Iron Treatment of High Arsenic Waters. Water Resources, 2001. 35(18): p. 4474-4479.

18. Ponder, S.M., J.G. Darab, and T.E. Mallouk, Remediation of Cr(VI) and Pb(II) Aqueous Solutions Using Supported, Nanoscale Zero-valent Iron. Environmental Science \& Technology, 2000. 34(12): p. 2564-2569.

19. Noubactep, C., Volke, P., Merkel, B. and G. Meinrath, Mitigation of Uranium in Effluents by Zero Valent Iron: The Role of Iron Corrosion Products. in International Conference on Radioactive Waste Management and Environmental Remediation, 8th. 2001. Bruges, Belgium: American Society of Mechanical Engineers.

20. Astrup, T., S.L.S. Stipp, and T.H. Christensen, Immobilization of Chromate from Coal Fly Ash Leachate Using an Attenuating Barrier Containing Zero-valent Iron. Environmental Science \& Technology, 2000. 34(19): p. 41634168.

21. Perey, J.R., Chui, P.C., Huang, C.P. and D.K. Cha, Zero-Valent Iron Pretreatment for Enhancing the Biodegradability of Azo Dyes. Water Environment Research, 2002. 74(3): p. 221-225.

22. United States Environmental Protection Agency, Permeable Reactive Subsurface Barriers for the Interception and Remediation of Chlorinated Hydrocarbon and Chromium (VI) Plumes in Ground Water. U.S. EPA Remedial Technology Fact Sheet, 1997(EPA/600/F-97/008): p. 1-4.

23. O'Hannesin, S.F. and R.W. Gillham, Long-Term Perfomance of an In Situ "Iron Wall" for Remediation of VOC's. Ground Water, 1998. 36(1): p. 164-170.

24. McMahon, P.B., K.F. Dennehy, and S.M. W., Hydraulic and Geochemical Performance of a Permeable Reactive Barrier Containing Zero-Valent Iron, Denver Federal Center. Ground Water, 1999. 37(3): p. 396-404.

25. Blowes, D.W., Ptacek, C.J., Cherry, J.A., Gillham, R.W. and W.D. Robertson, Passive Remediation of Groundwater Using In Situ Treatment Curtains. in GeoEnvironment 2000. 1995. New Orleans: American Society of Civil Engineers.

26. Wang, C.B. and W.X. Zhang, Synthesizing Nanoscale Iron Particles for Rapid and Complete Dechloronation of TCE and PCBs. Environmental Science \& Technology, 1997. 31(7): p. 2154-2156.

27. Lien, H.L. and W.X. Zhang, Transformation of Chlorinated Methanes by Nanoscale Iron Particles. Journal of Environmental Engineering, 1999. 125(11): p. 1042-1047.

28. Yang, C., E.E. Nuxoll, and E.L. Cussler, Reactive Barrier Films. AIChE Journal, 2001. 47(2): p. 295-302.

29. Clesceri, L.S., A.E. Greenberg, and A.D. Eaton, Standard Methods for the Examination of Water and Wastewater: Including Bottom Sediments and Sludges. 20 ed. 1998, New York: American Public Health Association, American Water Works Association \& Water Pollution Control Federation.

30. Gibbs, C.R., Characterization and Application of FerroZine Iron Reagent as a Ferrous Iron Indicator. Analytical Chemistry, 1976. 48(8): p. 1197-1201.

31. Shimotori, T., Nuxoll, E.E., Cussler, E.L. and W.A. Arnold, Polymer Membrane Containing FeO as a Contaminant Barrier. Environmental Science \& Technology, Submitted. 